\title{
POTENSI DAN PEMANFAATAN LIMBAH GERGAJIAN \\ PADA STAND KAYU DI DISTRIK MANOKWARI BARAT
}

\section{(Potency and Use of Wood Processing Waste at Wood Sortiment-Based Producer in West Manokwari Sub-District)}

\author{
Roy Rianto ${ }^{1}$ Wahyudi $^{1 凶}$ dan Dony A. Djitmau ${ }^{1}$ \\ Jurusan Kehutanan, Fakultas Kehutanan Universitas Papua Manokwari, Papua Barat, \\ 98314. Tlp/Fax: +62986211065 . \\ 『Penulis Korespondensi: Email: wahyudi.s.pono@gmail.com \\ Diterima: 30 Jan 2019| Disetujui: 27 Feb 2019
}

\begin{abstract}
Abstrak
Penelitian ini bertujuan untuk mengetahui jumlah, jenis limbah, volume dan komposisinya dari beberapa stand kayu di Distrik Manokwari Barat, Kabupaten Manokwari. Dalam pelaksanaan penelitian ini menggunakan metode deskriptif dan teknik survei melalui wawancara pada tiga stand kayu yaitu Farrel Jaya, Hati Murni 2 dan Hati Murni 1. Hasil penelitian memperlihatkan bahwa terdapat tiga jenis bahan baku kayu gergajian yaitu Merbau (Intsia sp.), Matoa (Pometia sp.) dan Rimba Campuran. Jenis limbah yang dihasilkan berupa sebetan, serbuk dan tatal. Dari sortimen olahan balok dan papan sebanyak $30 \mathrm{~m}^{3}$, dihasilkan limbah sebanyak $46,73 \% / \mathrm{m}^{3}$ dengan rata-rata jenis limbah sebetan sebanyak $7,47 \% / \mathrm{m}^{3}$, serbuk $6,80 \% / \mathrm{m}^{3}$ dan tatal $32,47 \% / \mathrm{m}^{3}$. Proses pengolahan lanjutan dari limbah masih belum terlihat dimana semua limbah biasanya hanya dibakar.
\end{abstract}

Kata kunci: limbah gergajian, stand kayu, sortimen, tatal, serbuk

\begin{abstract}
This study works toward the quantity, type, volume, and composition of wood waste that have been produced by three wood sortiment-based sellers in West Manokwari sub-district of Manokwari. Descriptive method through survey technique and interview based on designed questionnaires were carried out in order to generate data which are emanating from three small-scales of wood sortiment-based producers namely Farrel Jaya, Hati Murni 2 dan Hati Murni 1. The result revealed three types of round-wood raw material for producing sortiment such as Merbau (Intsia sp.), Matoa (Pometia sp.) and mixed wood. Wood wastes that were generated consisting of wood slab, sawdust, and wood chip. From the production of beam and board of $30 \mathrm{~m}^{3}$, it has been generated waste as much as 46.73 $\% / \mathrm{m}^{3}$ with an average of wood slab, sawdust, and wood chip were $7.47 \% / \mathrm{m}^{3}, 6,80 \% / \mathrm{m}^{3}$, $32,47 \% / m^{3}$ consecutively. There was no further use of waste from wood sortiment production, instead of burning.
\end{abstract}

Keywords: wood processing waste, sortiment-based producer, sortiment, slab, sawdust

\section{PENDAHULUAN}

Industri pengolahan kayu gergajian adalah proses terjadi perubahan kayu pertama kali dalam bentuk dolok menjadi kayu gergajian (sawn timber) atau disebut konversi kayu dalam bentuk papan, balok 
dan sortimen lainnya. Proses pengolahan kayu untuk pemenuhan kebutuhan selain menghasilkan kayu olahan juga menghasilkan limbah (Rachman dan Malik 2011; Fazaria 2013). Proses dalam pengolahan kayu gergajian meliputi empat proses yaitu : pembelahan utama (break down sawing), pembelahan kedua (resawing), pemerataan (trimming), dan pemotongan tepian (edging) akan menentukan kualitas dan sortimen dari kualitas kayu gergajian. Salah satu ciri khas dari industri pengolahan kayu adalah adanya produksi limbah yang sangat signifikan (Rachman dkk.1999).

Limbah pengergajian kayu adalah limbah atau sisa-sisa hasil pengolahan yang terjadi dilokasi penggergajian kayu. Sisa-sisa pengolahan kayu gergajian merupakan hasil sampingan dari penggergajian kayu seperti serbuk kayu gergajian, potong-potongan samping dan ujung, tetapi dapat berupa produk-produk yang tidak memenuhi kriteria kualitas yang ditentukan (Wahyudi 2013). Limbah penggergajian kayu di indonesia mancapai 1,4 juta $\mathrm{m}^{3}$ pertahun dengan total produksi kayu 2,6 juta $\mathrm{m}^{3}$ per tahun (Malik 2012).

Untuk wilayah Papua Barat, Kabupaten Manokwari khususnya Distrik Manokwari Barat memiliki stand gergajian kayu yang memproduksi balok dan papan. Hasil penggergajian balok dan papan akan menghasilkan berbagai jenis limbah berupa serbuk, sebetan, potongan ujung dan tatal. Namun informasi secara ilmiah mengenai limbah serta pengelolaannya belum tersedia, sehingga perlu dilakukan kajian mengenai jumlah dan tata cara pengelolaan limbah yang dihasilkan dari setiap stand pengergajian kayu di Distrik Manokwari Barat (Wahyudi 2013).
Stand kayu adalah industri primer hasil hutan kayu (IPHHK) yang status kepemilikannya perorangan, koperasi, BUMS, BUMN dan BUMD, dengan kapasitas produksi $6.000 \mathrm{~m}^{3}$ diberikan atas persetujuan oleh Gubernur. Sedangkan industri pengolahan hasil hutan kayu rakyat (IPKR) yang status kepemilikannya perorangan, koperasi dan BUMDES, dengan kapasitas sampai $2.000 \mathrm{~m}^{3}$ per tahun atas persetujuan Bupati/Walikota (P.13/Menlhk-II/ Tahun 2015). Tempat penampungan terdaftar kayu olahan (TPT-KO) adalah tempat untuk menampung kayu olahan milik perusahaan yang bergerak dalam bidang kehutanan atau perkayuan (PerMen LHK No 42 Tahun 2015). Penelitian ini bertujuan untuk mengetahui jumlah jenisjenis limbah dari stand kayu, volume dan komposisi limbah serbuk, sebetan dan tatal serta pemanfaatan dan pengelolaan limbah pada stand gergajian kayu di Distrik Manokwari Barat.

\section{METODE PENELITIAN}

Lokasi penelitian ini dilaksanakan pada 3 stand penggergajian kayu di Distrik Manokwari Barat, Kabupaten Manokwari Provinsi Papua Barat dengan lamanya waktu penelitian selama tiga bulan yakni dari bulan Juli hingga Oktober tahun 2018.

\section{Metode dan Teknik Penelitian}

Metode yang digunakan dalam penelitian ini adalah metode deskriptif dengan teknik survei yaitu dengan mengukur jumlah limbah serta pemanfaatan limbah di stand gergajian kayu di Distrik Manokwari Barat. 


\section{Variabel Pengamatan}

Dalam penelitian ini variabel yang diamati adalah jumlah volume jenis-jenis limbah seperti serbuk, sebetan dan tatal. Serta pemanfaatan limbah yang di lakukan pada setiap stand gergajian kayu.

\section{Teknik Pengumpulan Data}

Pengumpulan barbagai data yang diperlukan dalam penelitian ini adalah :

- Survei, penulis menerapkan metode ini dengan cara pengamatan langsung terhadap objek studi yaitu usaha stand kayu untuk mendapatkan informasi dan data yang dibutuhkan sebagai dasar penerapan potensi jenis limbah kayu di Distrik Manokwari Barat.

- Wawancara terstruktur dengan kuisioner yang telah disiapkan, yaitu percakapan dilakukan oleh dua pihak, yaitu pewawancara yang mengajukan pertanyaan dan terwawancara yang memberikan jawaban atas pernyataan tersebut untuk mendapatkan data dan informasi secara jelas dan lengkap sesuai dengan kusioner penelitian.

\section{Pengukuran Limbah Serbuk}

Limbah serbuk (sawdust) adalah limbah yang dihasilkan dari bekas sayatan (kerf) bilah gergaji, baik pada pembelahan, pemotongan ujung dan samping. Untuk mendapatkan volume limbah serbuk dengan cara memasukkan seluruh limbah ke dalam alat pengukuran volume limbah hingga penuh dan di tindis sampai padat untuk mendapatkan volume limbah disajikan pada Gambar 1. Hasil pengukuran 1 kotak sama dengan jumlah volume $=0,5 \mathrm{~m}^{3}$, serbuk limbah sudah tidak dipisahkan permasing-masing jenis kayu.

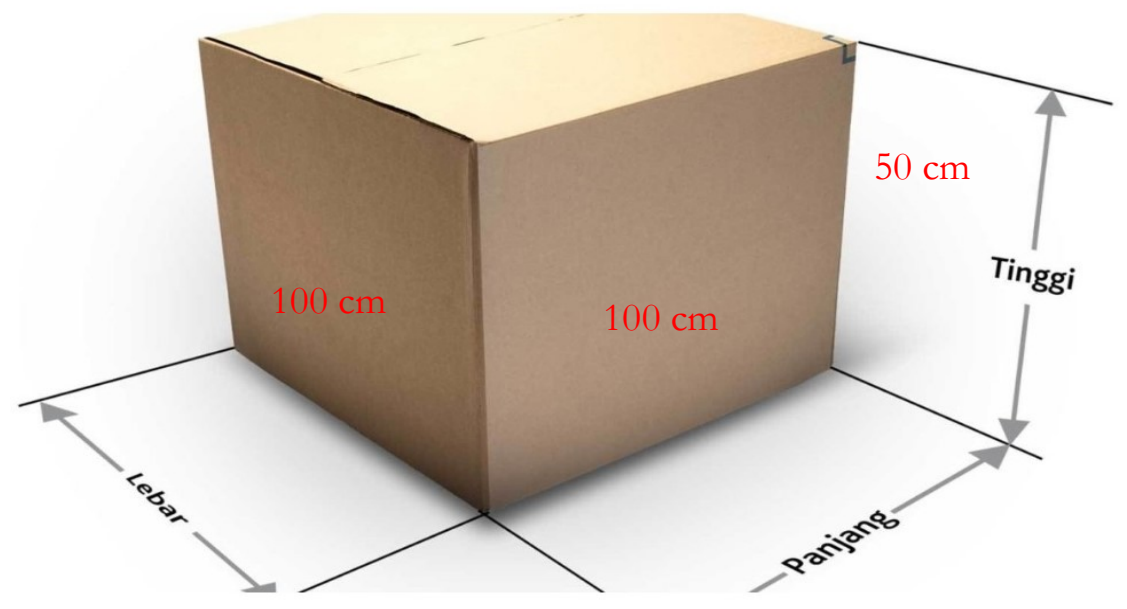

Gambar 1. Alat bantu untuk mengukur volume limbah

\section{Pengukuran Limbah Sebetan}

Limbah sabetan (offcut/slab) adalah limbah yang dihasilkan dari proses pelurusan (aligment) mesin gergaji utama dan gergaji ulang (resaw) untuk mendapatkan ukuran sortimen yang dihasilkan. Untuk mendapatkan volume limbah sebetan dengan cara masukkan limbah sebetan kedalam alat pengukuran volume jika limbah sebetan panjang maka dipotong sesuai dengan alat pengukuran kemudian masukkan limbah sebetan kedalam alat pengukuran hingga penuh 
untuk mendapatkan volume limbah sebetan, disajikan pada Gambar 1. Hasil pengukuran dinyatakan dalam satuan $\mathrm{m}^{3}$, apabila limbah sebetan memiliki dimensi yang tepat maka, dapat diukur dengan perhitungan volume biasa dan sudah tidak dipisahkan permasing-masing jenis kayu.

\section{Pengukuran Limbah Tatal}

Limbah tatal kayu (shaving) adalah limbah yang dihasilkan dari proses penghalusan permukaan kayu gergajian. Untuk mendapatkan volume limbah tatal dengan cara masukkan limbah tatal kedalam alat pengukuran volume hingga penuh dan ditindis sampai padat untuk mendapatkan volume limbah tatal, disajikan pada Gambar 1. Hasil pengukuran limbah tatal sudah tidak dipisahkan permasing-masing jenis kayu.

\section{Komposisi Limbah}

Komposisi limbah adalah persentase satu jenis limbah dibagi dengan jumlah total limbah dan dinyatakan dalam persen (\%). Komposisi limbah dihitung untuk seluruh stand kayu yang digunakan sebagai sampel penelitian.

$$
\frac{\text { Jumlah total limbah }}{\text { Satu jenis limbah }}
$$

\section{Analisis Data}

Data potensi volume limbah serbuk, sebetan, potongan ujung dan tatal. Serta pemanfaatan limbah yang dikumpulkan dapat diolah secara deskriptif dan ditampilkan dalam bentuk tabel, grafik dan gambar.

\section{HASIL DAN PEMBAHASAN}

\section{Jenis Kayu Pada Stand Kayu}

Jenis-jenis kayu pada tiga stand kayu di Distrik Manokwari Barat, yang dijadikan lokasi penelitian, selengkapnya dapat dilihat pada tabel 1.

\begin{tabular}{|c|c|c|c|c|c|}
\hline \multirow{2}{*}{ No Nama Stand Kayu } & \multirow{2}{*}{ Balok (cm) } & \multirow{2}{*}{ Papan (cm) } & \multicolumn{3}{|c|}{ Jenis Kayu } \\
\hline & & & a. (Merbau) & b.(Matoa) & c.(Rimba Campuran) \\
\hline \multirow[t]{4}{*}{1 Farrel jaya } & $-5 \times 5 \times 400$ & & - & $\mathrm{v}$ & $\mathrm{V}$ \\
\hline & $-5 \times 10 \times 400$ & & $v$ & $\mathrm{v}$ & v \\
\hline & $-10 \times 10 \times 300$ & & v & - & - \\
\hline & & $-2,5 \times 20 \times 400$ & - & - & v \\
\hline \multirow[t]{4}{*}{2 Hati murni 2} & $-5 \times 5 \times 400$ & & - & $\bar{v}$ & $\bar{v}$ \\
\hline & $-5 \times 10 \times 400$ & & - & v & - \\
\hline & - & & - & - & - \\
\hline & & $-2,5 \times 20 \times 400$ & - & $\mathrm{v}$ & $\mathrm{v}$ \\
\hline \multirow[t]{4}{*}{$\begin{array}{ll}3 & \text { Hati murni } 1\end{array}$} & $-5 \times 5 \times 400$ & & - & $\mathrm{v}$ & $\sqrt{ }$ \\
\hline & $-5 \times 10 \times 400$ & & - & $\mathrm{v}$ & - \\
\hline & $-10 \times 10 \times 300$ & & v & - & - \\
\hline & & $-2,5 \times 20 \times 400$ & - & v & v \\
\hline
\end{tabular}

Tabel 1. Jenis kayu pada ke tiga stand gergajian di wilayah Distrik Manokwari Barat

Dari hasil tabel 1 di atas menunjukkan bahwa jenis kayu yang digunakan pada stand kayu di Distrik Manokwari Barat untuk sortimen balok ukuran $5 \mathrm{~cm} \times 5 \mathrm{~cm}$ $\times 400 \mathrm{~cm}$ adalah jenis kayu Matoa dan Rimba Campuran, balok $5 \mathrm{~cm} \times 10 \mathrm{~cm} \times$ $400 \mathrm{~cm}$ adalah jenis kayu Merbau, Matoa dan Rimba Campuran. Balok $10 \mathrm{~cm} \times 10$ 
$\mathrm{cm} \times 300 \mathrm{~cm}$ adalah jenis kayu Merbau, dan untuk papan $2,5 \mathrm{~cm} \times 20 \mathrm{~cm} \times 400$ $\mathrm{cm}$ adalah jenis kayu Matoa dan Rimba Campuran.

\section{Asal Bahan Baku Kayu Gergajian}

Stand Kayu di Distrik Manokwari Barat merupakan usaha untuk memenuhi pasokan kayu bulat atau kayu olahan yang dibutuhkan dalam rangka untuk kepentingan Masyarakat dan kepentingan umum. Jenis bahan baku ini berasal dari daerah Pantai Utara Manokwari dengan jenis kayu yaitu Matoa dan Rimba Campuran. Sedangkan jenis bahan baku dari daerah Manokwari Selatan, Satuan Pemukiman, Windesi dan Bintuni dengan jenis kayu yaitu Merbau (Intsia sp.), Matoa (Pometia sp.) dan Rimba Campuran lainnya.

Hasil pengambilan data lapangan pada 3 (tiga) stand kayu gergajian di Distrik manokwari barat jenis kayu yang digunakan untuk bahan baku pengelolaan dengan balok ukuran $5 \mathrm{~cm} \times 5 \mathrm{~cm} \times 400$ $\mathrm{cm}, 5 \mathrm{~cm} \times 10 \mathrm{~cm} \times 400 \mathrm{~cm}, 10 \mathrm{~cm} \times 10$ $\mathrm{cm} \times 300 \mathrm{~cm}$ dan papan ukuran $2,5 \mathrm{~cm} \times$ $20 \mathrm{~cm} \times 400 \mathrm{~cm}$, menggunakan jenis kayu Merbau (Intsia sp.), Matoa (Pometia sp.) dan Rimba Campuran lainnya.

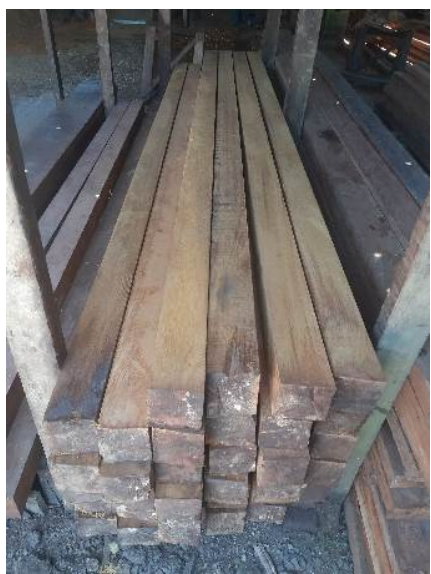

(a)

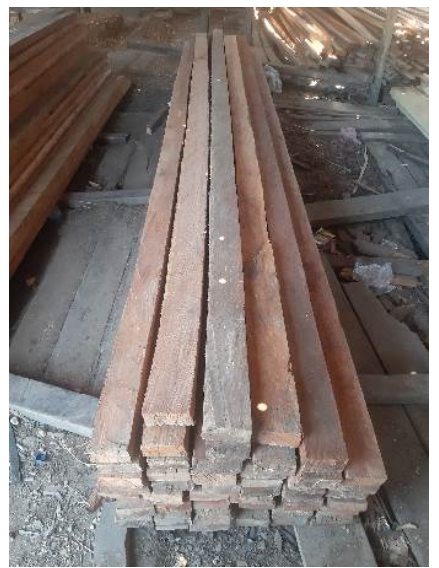

(b)

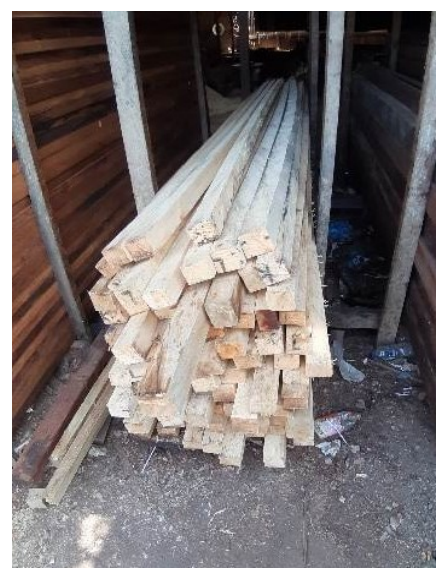

(c)

Gambar 2. Jenis kayu (a). Merbau (Intsia sp.), (b). Matoa (Pometia sp.) dan (c). Rimba Campuran lainnya.

\section{Jenis, Komposisi dan Volume Limbah Stand Kayu}

\section{Jenis Limbah}

Jenis-jenis limbah yang dihasilkan dari tiga stand kayu gergajian di Distrik Manokwari Barat dengan sortimen kayu balok ukuran $5 \mathrm{~cm} \times 5 \mathrm{~cm} \times 400 \mathrm{~cm}, 5$ $\mathrm{cm} \times 10 \mathrm{~cm} \times 400 \mathrm{~cm}, 10 \mathrm{~cm} \times 10 \mathrm{~cm} \times$
$300 \mathrm{~cm}$ dan papan ukuran $2,5 \mathrm{~cm} \times 20 \mathrm{~cm}$ $\times 400 \mathrm{~cm}$, dari keempat sortimen tersebut melewati 2 proses yaitu pemerataan dan pemotongan. Dalam pengambilan data pada stand kayu 1 Farrel Jaya dengan tiga kali ulangan sortimen balok/papan jumlah jenis limbah sebetan sebesar $0,74 \mathrm{~m}^{3}$ dengan nilai rata-rata $0,25 \mathrm{~m}^{3}$ dan persentasenya $6,43 \% / \mathrm{m}^{3}$. Jenis limbah 
serbuk sebesar $0,71 \mathrm{~m}^{3}$ dengan nilai ratarata $0,24 \mathrm{~m}^{3}$ dan persentasenya 6,17 $\% / \mathrm{m}^{3}$, dan jenis limbah tatal sebesar 3,03 $\mathrm{m}^{3}$ dengan nilai rata-rata $1,01 \mathrm{~m}^{3}$, dan persentasenya $26,35 \% / \mathrm{m}^{3}$.

Stand kayu 2 Hati Murni 2 dengan tiga kali ulangan sortimen balok/papan jumlah jenis limbah sebetan sebesar $0,62 \mathrm{~m}^{3}$ dengan nilai rata-rata $0,21 \mathrm{~m}^{3}$ dan persentasenya $6,53 \% / \mathrm{m}^{3}$. Jenis limbah serbuk sebesar $0,82 \mathrm{~m}^{3}$ dengan nilai ratarata $0,27 \mathrm{~m}^{3}$ dan persentasenya 8,63 $\% / \mathrm{m}^{3}$. Jenis limbah tatal sebesar $3,27 \mathrm{~m}^{3}$ dengan nilai rata-rata $1,09 \mathrm{~m}^{3}$ dan persentasenya $34,42 \% / \mathrm{m}^{3}$. Stand kayu 3 Hati Murni 1 dengan tiga kali ulangan sortimen balok/papan jumlah jenis limbah sebetan sebesar $0,88 \mathrm{~m}^{3}$ dengan nilai ratarata $0,29 \mathrm{~m}^{3}$ dan persentasenya 9,78 $\% / \mathrm{m}^{3}$, jenis limbah serbuk sebesar 0,51 $\mathrm{m}^{3}$ dengan nilai rata-rata $0,17 \mathrm{~m}^{3}$ dan persentasenya $5,67 \% / \mathrm{m}^{3}$. Jenis limbah tatal sebesar $3,06 \mathrm{~m}^{3}$ dengan nilai ratarata $1,02 \mathrm{~m}^{3}$ dan persentasenya $34 \% / \mathrm{m}^{3}$. Sedangkan contoh jenis limbah pada stand kayu berupa : sebetan, serbuk dan tatal.

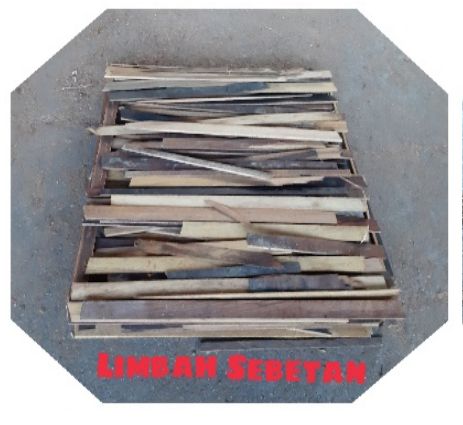

(a)

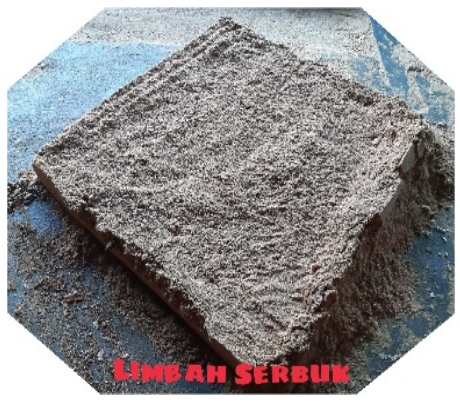

(b)

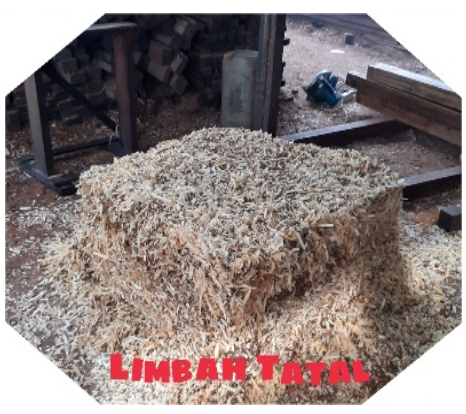

(c)

Gambar 3. Jenis limbah yang dihasilkan yang terdiri dari: (a) sebetan, (b) serbuk dan (c) tatal.

\section{Komposisi Limbah}

Komposisi limbah adalah persentase satu jenis limbah dibagi dengan jumlah total limbah dan dinyatakan dalam persen (\%). Hasil pengambilan data dari tiga stand kayu di Distrik Manokwari Barat terlihat bahwa pada stand kayu 1 Farrel Jaya, sortimen balok $5 \mathrm{~cm} \times 5 \mathrm{~cm} \times 400$ $\mathrm{cm}\left(3 \mathrm{~m}^{3}\right)$ dengan jenis limbah yang dihasilkan yaitu sebetan sebesar $0,32 \mathrm{~m}^{3}$ dengan persentase $10,67 \% / \mathrm{m}^{3}$, dan limbah serbuk $0,20 \mathrm{~m}^{3}$ dengan persentase $6,67 \% / \mathrm{m}^{3}$. Balok $5 \mathrm{~cm} \times 10 \mathrm{~cm} \times 400 \mathrm{~cm}$ $\left(3 \mathrm{~m}^{3}\right)$ jenis limbah yang dihasilkan yaitu sebetan $0,21 \mathrm{~m}^{3}$ dengan persentase 7,00
$\% / \mathrm{m}^{3}$, limbah serbuk $0,33 \mathrm{~m}^{3}$ dengan persentase $11,00 \% / \mathrm{m}^{3}$ dan limbah tatal $1,29 \mathrm{~m}^{3}$ dengan persentase $43.00 \% / \mathrm{m}^{3}$. Balok $10 \mathrm{~cm} \times 10 \mathrm{~cm} \times 300 \mathrm{~cm}\left(3 \mathrm{~m}^{3}\right)$ jenis limbah yang dihasilkan yaitu tatal $1,04 \mathrm{~m}^{3}$ dengan persentase $34,67 \% / \mathrm{m}^{3}$. dan sortimen papan $2,5 \mathrm{~cm} \times 20 \mathrm{~cm} \times 400$ $\mathrm{cm}\left(2,5 \mathrm{~m}^{3}\right)$ dengan jenis limbah yang dihasilkan yaitu sebetan $0,21 \mathrm{~m}^{3}$ dengan persentase $8,40 \% / \mathrm{m}^{3}$, serbuk $0,18 \mathrm{~m}^{3}$ dengan persentase $7,20 \% / \mathrm{m}^{3}$ dan tatal $1,08 \mathrm{~m}^{3}$ dengan persentase $43,20 \% / \mathrm{m}^{3}$.

Stand kayu 2 Hati Murni 2 sortimen balok $5 \mathrm{~cm} \times 5 \mathrm{~cm} \times 400 \mathrm{~cm}\left(2,5 \mathrm{~m}^{3}\right)$ 
dengan jenis limbah yang dihasilkan yaitu sebetan $0,23 \mathrm{~m}^{3}$ dengan persentase 9,20 $\% / \mathrm{m}^{3}$, serbuk $0,35 \mathrm{~m}^{3}$ dengan persentase $14,00 \% / \mathrm{m}^{3}$. Balok $5 \mathrm{~cm} \times 10 \mathrm{~cm} \times 400$ $\mathrm{cm}\left(5 \mathrm{~m}^{3}\right)$ dengan jenis limbah yang dihasilkan yaitu sebetan $0,19 \mathrm{~m}^{3}$ dengan persentase $3,80 \% / \mathrm{m}^{3}$, serbuk $0,32 \mathrm{~m}^{3}$ dengan persentase $6,40 \% / \mathrm{m}^{3}$ dan tatal 2,4 $\mathrm{m}^{3}$ dengan persentase $48,00 \% / \mathrm{m}^{3}$, dan sortimen papan ukuran $2,5 \mathrm{~cm} \times 20 \mathrm{~cm} \times$ $400 \mathrm{~cm}\left(2 \mathrm{~m}^{3}\right)$ dengan jenis limbah yang dihasilkan yaitu sebetan $0,20 \mathrm{~m}^{3}$ dengan persentase $10,00 \% / \mathrm{m}^{3}$, serbuk $0,15 \mathrm{~m}^{3}$ dengan persentase $7,50 \% / \mathrm{m}^{3}$ dan tatal $0,87 \mathrm{~m}^{3}$ dengan persentase limbah 43,50 $\% / \mathrm{m}^{3}$.

Stand kayu 3 Hati Murni 1 sortimen balok $5 \mathrm{~cm} \times 5 \mathrm{~cm} \times 400 \mathrm{~cm}\left(2 \mathrm{~m}^{3}\right)$ dengan jenis limbah yang dihasilkan yaitu sebetan $0,30 \mathrm{~m}^{3}$ dengan persentase $15,00 \% / \mathrm{m}^{3}$ dan serbuk $0,19 \mathrm{~m}^{3}$ dengan persentase $9,50 \% / \mathrm{m}^{3}$. Balok $5 \mathrm{~cm} \times 10$ $\mathrm{cm} \times 400 \mathrm{~cm}\left(2,5 \mathrm{~m}^{3}\right)$ dengan jenis limbah yang dihasilkan yaitu sebetan 0,32 $\mathrm{m}^{3}$ dengan persentase $12,80 \% / \mathrm{m}^{3}$, serbuk $0,17 \mathrm{~m}^{3}$ dengan persentase $6,80 \% / \mathrm{m}^{3}$ dan tatal $1,05 \mathrm{~m}^{3}$ dengan persentase 42,00 $\% / \mathrm{m}^{3}$. Balok $10 \mathrm{~cm} \times 10 \mathrm{~cm} \times 300 \mathrm{~cm}$ $\left(2,5 \mathrm{~m}^{3}\right)$ dengan jenis limbah yang dihasilkan yaitu tatal $1,16 \mathrm{~m}^{3}$ dengan persentase $46,40 \% / \mathrm{m}^{3}$. Sortimen papan $2,5 \mathrm{~cm} \times 20 \mathrm{~cm} \times 400 \mathrm{~cm}\left(2 \mathrm{~m}^{3}\right)$ dengan jenis limbah yang dihasilkan yaitu sebetan $0,26 \mathrm{~m}^{3}$ dengan persentase 13,00 $\% / \mathrm{m}^{3}$, serbuk $0,15 \mathrm{~m}^{3}$ dengan persentase $7,50 \% / \mathrm{m}^{3}$ dan tatal $0,85 \mathrm{~m}^{3}$ dengan persentase $42,50 \% / \mathrm{m}^{3}$.

\section{Volume Limbah}

Stand kayu adalah menggergaji kayu log atau penghara di lokasi dimana kayu atau pohon tersebut di tebang, melewati pembelahan utama dan pembelahan kedua, kemudian kayu dibentuk menjadi balok dan papan berbagai ukuran dan diangkut menuju stand kayu untuk dilakukan pemerataan dan pemotongan menggunakan mesin. Kemudian melewati 2 proses yaitu pemerataan dan pemotongan dari hasil tersebut menghasilkan limbah. Untuk menghitung volume jenis limbah menggunakan alat bantu volume limbah pada tiga stand kayu di Distrik Manokwari Barat.

Hasil volume limbah pada tiga stand kayu di Distrik manokwari barat disajikan pada tabel 2. Pertama stand kayu Farrel Jaya dari sortimen balok dan papan sebanyak $\left(11,5 \mathrm{~m}^{3}\right)$ dan jumlah total jenis limbah yang dihasilkan $4,48 \mathrm{~m}^{3}$ dengan persentase jenis limbah sebetan 6,43 $\% / \mathrm{m}^{3}$, serbuk $6,17 \% / \mathrm{m}^{3}$ dan tatal 26,35 $\% / \mathrm{m}^{3}$. kedua stand kayu Hati Murni 2 dari sortimen balok dan papan sebanyak $(9,5$ $\mathrm{m}^{3}$ ) dan jumlah total jenis limbah yang dihasilkan 4,71 $\mathrm{m}^{3}$ dengan persentase jenis limbah sebetan $6,53 \% / \mathrm{m}^{3}$, serbuk $8,63 \% / \mathrm{m}^{3}$ dan tatal $34,42 \% / \mathrm{m}^{3}$. ketiga stand kayu Hati Murni 1 dari sortimen balok dan papan sebanyak $\left(9 \mathrm{~m}^{3}\right)$ dan jumlah total jenis limbah yang dihasilkan $4,45 \mathrm{~m}^{3}$ dengan persentase jenis limbah sebetan $9,78 \% / \mathrm{m}^{3}$, serbuk $5,67 \% / \mathrm{m}^{3}$ dan tatal $34,00 \% / \mathrm{m}^{3}$. dari penjelasan diatas jenis limbah tertinggi pada 3 stand kayu di Distrik manokwari barat adalah jenis limbah tatal, ini di karenakan pada saat limbah tatal dimasukkan pada alat bantu limbah tatal tidak bisa padat satu sama yang lain dan hasil pengukurann limbah akan bias dan susah dipadatkan. Sehingga dengan demikian limbah tatal banyak dari kedua jenis limbah sebetan dan serbuk. 
Tabel 2. Volume jenis limbah pada ke tiga stand kayu di wilayah Distrik Manokwari Barat

\begin{tabular}{cllccc}
\hline No Nama Stand Kayu & Jenis Limbah & jumlah $\left(\mathrm{m}^{3}\right)$ & rata-rata $\left(\mathrm{m}^{3}\right)$ & Persen $(\%) / \mathrm{m}^{3}$ \\
\hline 1 & Farrel jaya & sebetan & 0.74 & 0.25 & 6.43 \\
& & serbuk & 0.71 & 0.24 & 6.17 \\
& & tatal & 3.03 & 1.01 & 26.35 \\
\hline & total & 4.48 & 1.49 & 38.96 \\
\hline 2 & Hati murni 2 & sebetan & 0.62 & 0.21 & 6.53 \\
& serbuk & 0.82 & 0.27 & 8.63 \\
& & tatal & 3.27 & 1.09 & 34.42 \\
\hline & & total & 4.71 & 1.57 & 49.58 \\
\hline 3 & Hati murni 1 & sebetan & 0.88 & 0.29 & 9.78 \\
& & serbuk & 0.51 & 0.17 & 5.67 \\
& & tatal & 3.06 & 1.02 & 34.00 \\
\hline & & total & 4.45 & 1.48 & 49.44 \\
\hline
\end{tabular}

Data primer 2019

\section{Pemanfaatan Limbah}

Limbah dari industri penggergajian, baik yang skala besar, menengah dan kecil dapat dimanfaatkan untuk berbagai tujuan, dari produk kerajinan, bahan baku bangunan, penunjang peternakan dan pertanian. Tetapi pemanfaatan jenis limbah sebetan, serbuk dan tatal yang dilakukan 3 stand kayu gergajian di Distrik Manokwari barat adalah dibakar, dibuang serta dijual. Untuk limbah tatal dan serbuk dibuang tetapi ada yang dijual untuk penunjang peternakan ayam dan pabrik tahu dengan penjualan harga Rp. 100.000 - 200.000 per rit. Limbah sebetan dengan dimensi tebal $>1 \mathrm{~cm}$ di jual dengan harga Rp. 5.000 - 10.000 per lembar yang digunakan untuk pembuatan pagar, kandang dan dimensi $<1 \mathrm{~cm}$ digunakan masyarakat untuk kayu bakar, sedangkan limbah serbuk dan tatal jika banyak di lokasi produksi maka, ada yang di bakar karena sudah tidak ada tempat untuk menampung limbah tersebut. Dari ke-3 stand kayu gergajian belum adanya pengelolaan limbah yang dilakukan secara baik dan benar.

\section{DAFTAR PUSTAKA}

Fazaria DA. 2013. Analisis manfaat ekonomi pengolahan serbuk gergaji. (skripsi). Institute Pertanian Bogor.

Kementerian Lingkungan Hidup dan Kehutanan Republik Indonesia. 2015. Keputusan Menteri Lingkungan Hidup dan Kehutanan No P.13/MenlhkII/2015 tentang Izin Usaha Industri Primer Hasil Hutan, Jakarta.

Kementerian Lingkungan Hidup dan Kehutanan Republik Indonesia. 2015. Keputusan Menteri Lingkungan Hidup dan Kehutanan No P.42/MenlhkSetjen/2015 tentang Penatausahaan Hasil Hutan Kayu Yang Berasal Dari Hutan Tanaman Pada Hutan Produksi, Jakarta.

Malik U. 2012. Penelitian berbagai jenis kayu limbah pengolahan untuk pemilihan bahan baku briket arang. Junal Imiah Edu Research, 1(2): 2126. 
Rachman O dan Malik J. 2011. Penggergajian dan pemesinan kayu untuk industri perkayuan Indonesia. Balai Penelitian dan Pengembangan Kehutanan, Jakarta.

Rachman O. 1999. Bahan baku dan proses penggergajian kayu. Pusat
Penelitian hasil Hutan. Badan Penelitian dan Pengembangan Kehutanan dan Perkebunan Bogor.

Wahyudi. 2013. Dasar-dasar penggergajian kayu. Yogyakarta: Pohon Cahaya. 